\title{
Study on the abrasive resistance of Polylactic acid fiber sand barrier
}

\author{
Jingxin Shen ${ }^{1, a}$, Weijie Yuan ${ }^{* 2, b}, Y_{i} \mathrm{Yu}^{*}{ }^{3, \mathrm{c}}$ and Xiaomin Song ${ }^{4, \mathrm{~d}}$ \\ ${ }^{1}$ International Centre for Bamboo and Rattan, Beijing 100102, China \\ ${ }^{2}$ Forestry Experiment Center of North China, Chinese Academy of Forestry, Beijing 102300, China \\ ${ }^{3}$ International Centre for Bamboo and Rattan, Beijing 100102, China \\ ${ }^{4}$ International Centre for Bamboo and Rattan, Beijing 100102, China \\ byuanweijie717@163.com, 'cyuicbr@163.com,
}

\begin{abstract}
Keywords: PLA sand barriers; Abrasion resistance; Martindale Abrasion; Taber Abraser
Abstract. Life length of PLA sand barrier shall be influenced under wind-drift sand. This study researches the law of abrasion performance to provide theoretical underpinnings in predicting life length of PLA sand barrier. This study tests the abrasion performance of PLA sand Barrier by applying Martindale Abrasion Method and Taber Abraser. The abrasion resistance is evaluated by count cycle under damage, mass loss and EASM. The statistical analysis demonstrates that there is significant difference among cycle counts under different level of loads, and the numbers of convolution is negatively related to loads. However, the linear relationship between loads and number is not that strong; Mass loss is positively related to numbers of convolution and they get well linear relationship - the mass loss goes up with increased numbers of convolution; With the number of convolution increasing, the surface configuration goes messed.
\end{abstract}

\section{Introduction}

China is the country that faces the most serious desertification. After years of efforts, people have slowed down the expansion of desertification. Desertification seriously endangers the ecological environment of the people, income and living standards. Therefore, desertification has become a global environmental and resource issue of concern to the international community [1]. Now, people combat desertification through biological measures and engineering measures. But biological measures are considered as the main measures and engineering measures are taken as auxiliary measures. In the extreme environment of the quicksand area, the biological measures could be effectively implemented unless the environment is improved. Therefore, engineering measures have an irreplaceable role. The principles of engineering measures is to prevent the sand hazard by solidifying, anting, transporting, directing the sand [1-3]. According to the different materials, mechanical sand barrier can be divided into two categories: traditional sand barrier and new sand barrier. The traditional sand barrier in desertification control plays a significant role. A lot of people is research the traditional of sand barrier and have achieved some results [2-7]. Due to the material factors, traditional branches, straw, wicker sand barrier are perishable and lodging. In order to ensure the effect of sand barrier, replacing sand barrier frequently increases the cost. With the development of science and technology, new material sand barrier is used in the field of desertification. Polylactic acid fiber (PLA) sand barrier is a new type of sand barrier. Polylactic acid fiber can be completely degraded into carbon dioxide and water, it will not produce any pollution to the environment. Many domestic researchers have done some research on PLA sand barrier prevention effect in the desert, for example: the effect of wind resistance [11], the influence of wind erosion and sand burial [12], the influence of soil hardness [13] and soil moisture content [14]. Weijie Yuan et al [15, 16] study on the degradation and aging of PLA sand barrier. Ling Cheng et al [17] made some research on the mechanical properties of PLA. Yong Zhai et al [18, 19] has done some research on the performance of different kinds of blended polylactic acid fiber. In the field of desertification prevention and control, there is less research on the abrasive resistance of PLA sand barrier. In the process of using, PLA sand barrier by abrasive sand flow, will shorten the service life, so it is necessary to do some research on the wear resistance. In this paper, the abrasive resistance of PLA 
sand barrier is studied through experiments, which provides a theoretical basis for predicting the service life of PLA sand barrier in desertification control basin.

\section{Materials}

Polylactic acid material, adopted by the sand barrier, is produced with corn as raw material, which was made by polycondensation melt spinning after fermentation; The molecular formula is $\left(\mathrm{C}_{3} \mathrm{H}_{4} \mathrm{O}_{2}\right)_{n}$. PLA sand barrier is a cylindrical knitted fabric. Under the unfilled condition the sand barrier's width is $8 \mathrm{~cm}$; under the filled condition, height ranges from 10 to $13 \mathrm{~cm}$.

Before the experiment, the basic indexes (Table 1) of PLA fabric were measured. PLA fabric thickness reference ISO5084; 1996 Textile and Textile products thickness determination. The thickness of the fabric was measured by a SDL Atlas Mo34A thickness gauge, the presser foot area was $20 \mathrm{~cm}^{2}$ and the weight was 1000pa. The density of sand barrier is based on Yao Mu's Textile Materials Science [20]. His book is a predetermined density of the knitted fabric of $5 \mathrm{~cm}$ coils.

Table 1 The basic parameters of the PLA sand barrier

\begin{tabular}{cccccc}
\hline Fabric & Tisse & $\begin{array}{c}\text { Count }(\text { tex } \\
\text { ( }\end{array}$ & $\begin{array}{c}\text { Density }( \\
\text { number of coils } \\
15 \mathrm{~cm})\end{array}$ & $\begin{array}{c}\text { Proportion }\left(\begin{array}{c}\text { Thickness }( \\
\left.\mathrm{g} / \mathrm{cm}^{3}\right)\end{array}\right. \\
\mathrm{mm})\end{array}$ \\
\hline $\begin{array}{c}\text { PLA Sand } \\
\text { Barrier }\end{array}$ & Cross Grain & 16.7 & 80 & 1.25 & 0.41 \\
\hline
\end{tabular}

\section{Experimental Conditions}

The whole experiment was carried out at a temperature of $20^{\circ} \mathrm{C} \pm 2$ and at an atmospheric humidity of $65 \% \pm 2 \%$. Since the PLA sand barrier is preserved in rolls, the cut specimen starts at $1 \mathrm{~m}$ from the end. The sample was placed in a constant temperature and humidity chamber at a temperature of $20^{\circ} \mathrm{C} \pm 2{ }^{\circ}$ $\mathrm{C}$ and at an atmospheric humidity of $65 \% \pm 2 \%$, and the humidity control time was 24 hours or more.

\section{Standards and Instruments}

The criteria PLA sand barrier Damage Test and Quality Loss Test adopted refers to ASTM D3884 Fabric Abrasive Test, ISO 12947.2-1998 Textiles - Determination of abrasion resistance of fabrics using the Martindale method Part 2: Specimens Determination of damage, ISO 12947.3-1998 Textiles - Determination of abrasion resistance of fabrics using the Martindale method - Part 3: Determination of mass loss. The main instruments are the abrasive instrument (Taber 5155), constant temperature and humidity box (HwS-250), electronic balance (Sartorius BP221S type, precision $0.1 \mathrm{mg}$ ), thickness gauge, and FEG-XL30 ESEM environmental scanning electron microscope.

\section{Methods}

PLA Sand Barrier Breakage Test. PLA sand barrier samples are placed in constant temperature and humidity box (temperature $20{ }^{\circ} \mathrm{C} \pm 2{ }^{\circ} \mathrm{C}$, atmospheric humidity of $65 \% \pm 2 \%$ ) for 24 hours or more before the test. The entire experimental procedure was carried out in a standard atmospheric environment (temperature $20^{\circ} \mathrm{C} \pm 2{ }^{\circ} \mathrm{C}$, atmospheric humidity $65 \% \pm 2 \%$ ). The number of revolutions was set under the action of three forces $(2.45 \mathrm{~N}, 7.35 \mathrm{~N}, 12.25 \mathrm{~N})$. Each experiment is scheduled to repeat 5 times. The criteria of judging breakage of sand barrier, is the breakage of single yarn. When the yarn is worn, the number of revolutions was recorded to provide data for statistical analysis.

Determination of Mass Moss of PLA Sand Barrier. PLA sand barrier samples are placed in constant temperature and humidity box (temperature $20{ }^{\circ} \mathrm{C} \pm 2{ }^{\circ} \mathrm{C}$, atmospheric humidity of $65 \% \pm 2 \%$ ) 
for 24 hours or more humidity control. The entire experimental procedure was carried out in a standard atmospheric environment (temperature $20{ }^{\circ} \mathrm{C} \pm 2{ }^{\circ} \mathrm{C}$, atmospheric humidity $65 \% \pm 2 \%$ ). We set the number of revolutions of the abraser to $300 \mathrm{rpm}, 600 \mathrm{rpm}, 900 \mathrm{rpm}, 1200 \mathrm{rpm}$. After the test is completed, the test samples are placed in a box with constant temperature and humidity (temperature $20{ }^{\circ} \mathrm{C} \pm 2 \stackrel{\circ}{ } \mathrm{C}$, atmospheric humidity of $65 \% \pm 2 \%$ ) for 24 hours or more, then the weight of the sample was recorded . Each experiment is scheduled to repeat 5 times.

EASM Observation. In this study, the structural changes of the surface of PLA sand barrier under bleached condition of $0 \mathrm{rpm}, 300 \mathrm{rpm}, 600 \mathrm{rpm}, 900 \mathrm{rpm}$ and $1200 \mathrm{rpm}$ were observed. The scope magnification of test was 150 times.

\section{Results and Analysis}

Table 2 The number of revolutions when the sand barrier is worn

\begin{tabular}{cccc}
\hline \multirow{2}{*}{ Fabric } & \multicolumn{3}{c}{ Breaking number of turn under different loads $(\mathrm{r})$} \\
\cline { 2 - 4 } & $2.45 \mathrm{~N}$ & $7.35 \mathrm{~N}$ & $12.25 \mathrm{~N}$ \\
\hline PLA Sand Barrier & 1415 & 353 & 85 \\
\hline
\end{tabular}

Note: The data in the table is the average of 5 sample tests.

Effect of Load on PLA Sand Barrier. We can see in table 2. As the load increases, the number of turns when the fabric is worn is reduced. When the load is $2.45 \mathrm{~N}$, the number of revolutions is $1415 \mathrm{r}$; when the load is 12.25 , the number of revolutions is 85 turns. The former is the latter 16.6 times. We convert the data in Table 1 into a line chart (Fig.1).

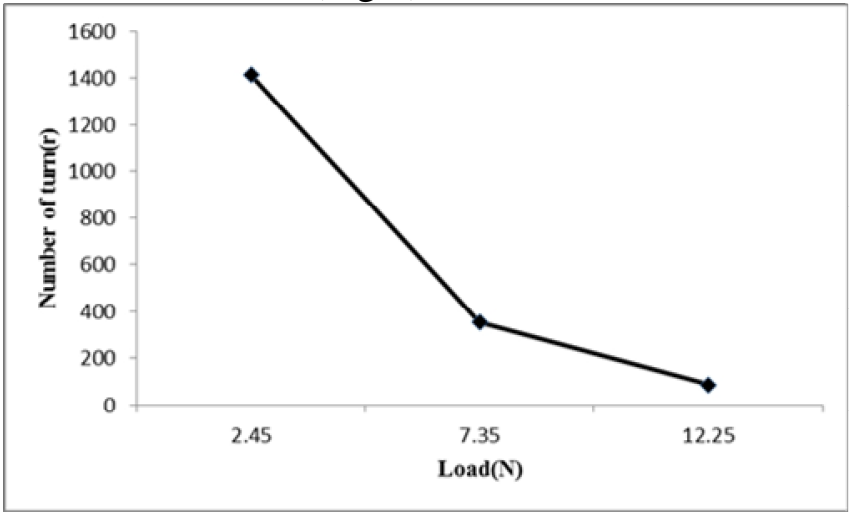

Fig. 1 The number of revolutions when the sand barrier is worn

The results are shown in Figure 1. With the load increase, the number of turns decreases under the situation that the PLA sand barrier is broken. The speed of decline slows down. This situation could be attributed to the fact that the fabric surface is changed when the fabric is polished and the friction coefficient between the friction wheel and the fabric is changed. Another possibility is that the PLA sand barrier is relatively fluffy and soft, and easy to deform under larger loads, increasing the contact area between the friction wheel and the fabric and making the fabric more easily worn. So the greater the load, the smaller the number of revolutions is.

The one-way ANOVA between load and revolution is done via spss19.0 software. The results $(\mathrm{F}=339.042, \mathrm{P}<0.001)$ show that there is a significant difference between the load and the number of revolutions. Different loads have a significant effect on the number of revolutions when PLA sand barrier is worn.

Pearson correlation analysis was used to analyze the correlation between load and the number of revolutions when PLA sand barrier is worn. The results( $\mathrm{r}=-0.9454)$ show that there is a negative correlation between the load and the number of revolutions. As the load increase, the number of revolutions will be further smaller.

The correlation analysis and linear regression between load and revolution are done by origin 8.0 software. The results show that there is a linear relationship between the load and the number of revolutions. 
$\mathrm{y}=1615.1667-135.71429 \mathrm{x}, \mathrm{r} 2=0.78763$.

$\mathrm{x}$ : The number of revolutions when PLA sand barrier is worn, $\mathrm{r}$;

y: Load, N;

r: Correlation coefficient.

It can be seen from the formula (1) that the number of revolutions will decrease with the increase of load.

Table 3 Quality loss of sand barrier at different number of revolutions

\begin{tabular}{|c|c|c|c|c|c|}
\hline \multirow{2}{*}{ Number } & \multirow{2}{*}{$\begin{array}{l}\text { Pre-friction } \\
\text { Quality (g) }\end{array}$} & \multicolumn{4}{|c|}{ The Weight after Abrasive (g) } \\
\hline & & $300 \mathrm{r}$ & $600 \mathrm{r}$ & $900 \mathrm{r}$ & $1200 \mathrm{r}$ \\
\hline 1 & 3.2100 & 3.2059 & & & \\
\hline 2 & 3.1103 & & 3.1001 & & \\
\hline 3 & 3.1796 & & & 3.1651 & \\
\hline 4 & 3.1514 & & & & 3.1286 \\
\hline
\end{tabular}

Note: The data in the table is the average of 5 sample tests.

Results and Analysis of Quality Abrasive of PLA Sand Barrier In order to reduce the experimental error, each sample does not repeat the abrasive. The quality loss in Table 3 is converted into mass loss rate. The linear relationship between the mass loss rate and the number of revolutions was shown in the figure2. The results are shown in Figure 2 that the mass loss rate increases with increasing number of revolutions. This result is consistent with Ren Rufen's conclusion.

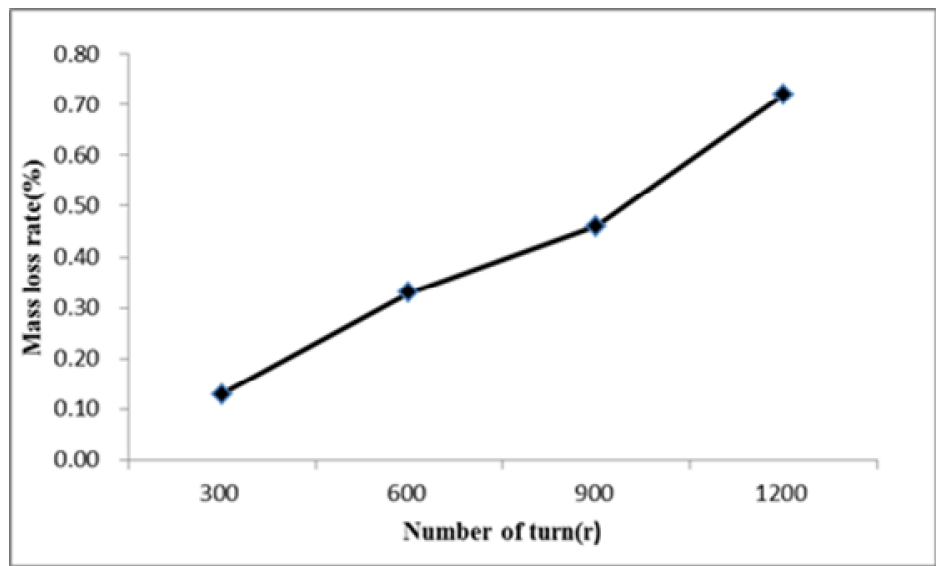

Fig.2 Quality loss of sand barrier at different number of revolutions

Pearson correlation analysis was used to analyze the correlation between the number of abrasive and mass loss. The result( $(\mathrm{r}=0.992 * *, \mathrm{P}<0.01))$ shows that there is a significant positive correlation between the different number of abrasive and mass loss. This indicates that the mass loss of PLA sand barrier will continue to increase as the number of revolutions increases. There is a significant positive correlation between the number of revolutions and the mass loss rate. The correlation analysis and linear regression between the number of revolutions and the mass loss rate are done by origin 8.0 software.

$\mathrm{y}=-0.065+6.33333 \mathrm{E}-4 \mathrm{x}, \mathrm{r} 2=0.97628$.

$\mathrm{x}$ : The number of revolutions;

y: Mass loss rate;

r: Correlation coefficient.

The results show that there is a strong positive correlation between the mass loss rate and the abrasive speed. The number of abrasive has a significant effect on the quality loss rate of PLA sand barrier. The loss rate of PLA sand barrier quality increases with the increase of number of abrasive.

Results and Analysis of EASM Scanning. PLA sand barrier is polished under 0r, 300r, 600r, 900r, 1200r (a-e). The apparent morphology of PLA sand barrier after grinding was observed under electron microscope (Fig.3). It can be seen from Figure 3, sand barrier is polished, and the yarn has different 
degrees of fracture. The more the rotations, the more the yarn breaks. The breakage of the yarn made the surface of the sand barrier became messy.

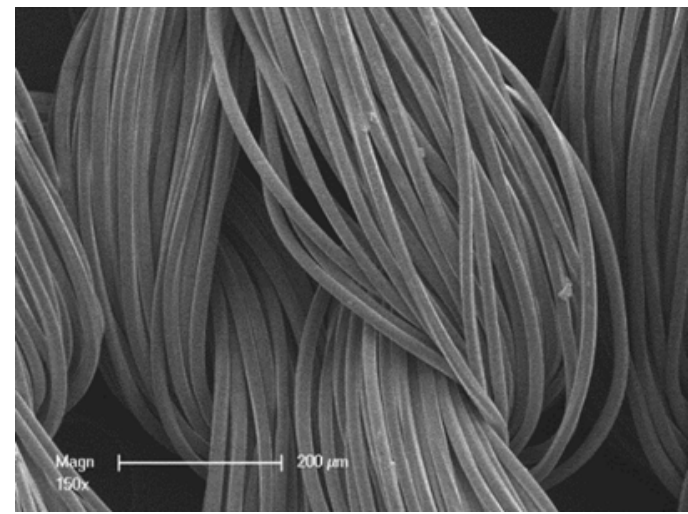

a

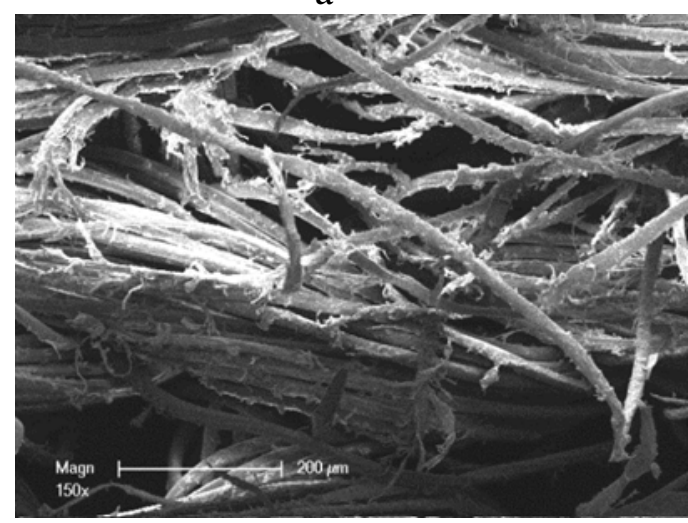

c

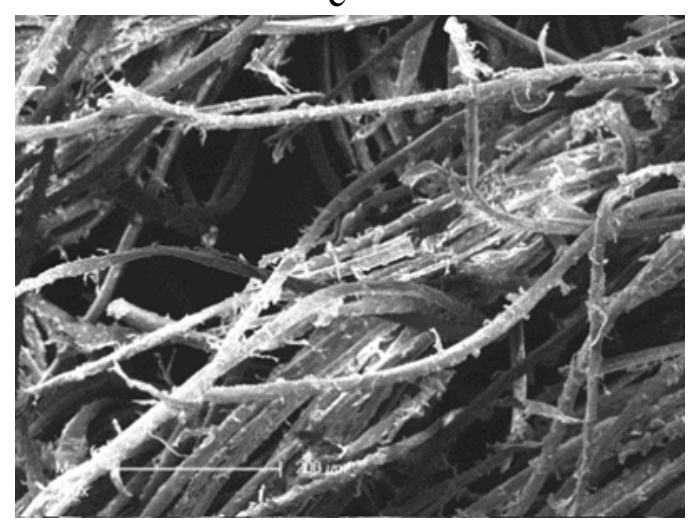

e

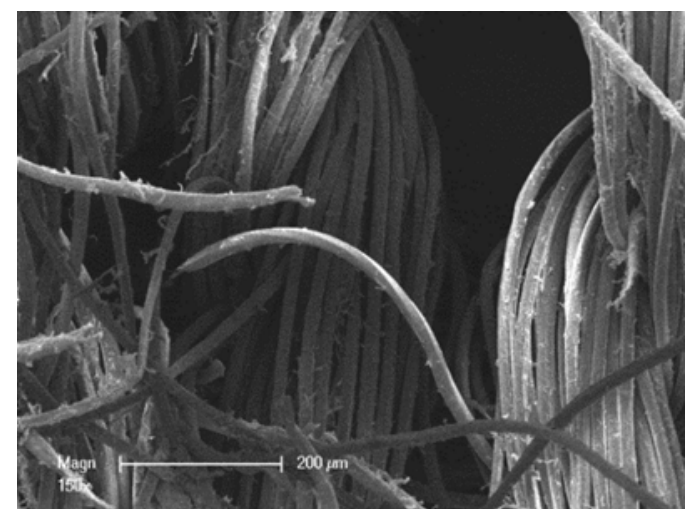

b

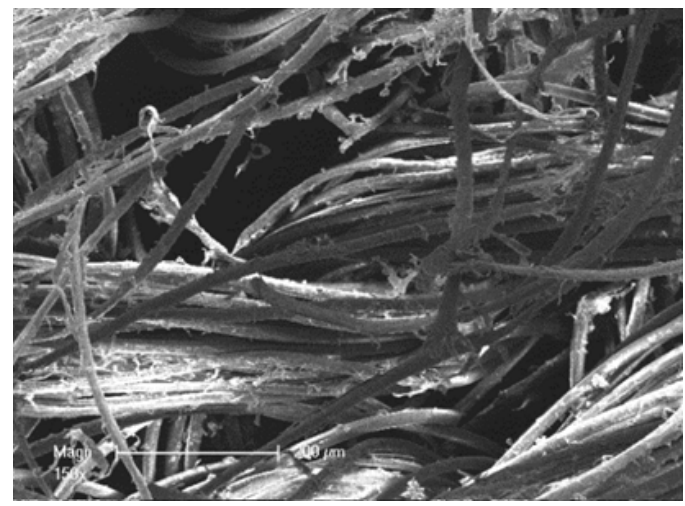

d

Fig.3 The apparent morphology of polylactic acid fiber sand barrier at different wear levels

\section{Conclusions}

(1) The abrasive resistance of PLA sand barrier differs under different loads. As the load increases, the number of turns when the fabric is worn is reduced.

(2) By analyzing the correlation between the load and the number of revolutions, it shows that there is a negative correlation between the load and the number of revolutions. The regression equation is $y=1615.1667-135.71429 x, r^{2}=0.78763$.

(3) The correlation and linear regression analysis among the number of revolutions and the mass loss rate of PLA sand barrier were carried out. There is a significant positive correlation and linear relationship between the mass loss rate and the number of revolutions. The regression equation is $\mathrm{y}=-0.065+6.33333 \mathrm{E}-4 \mathrm{x}, \mathrm{r}^{2}=0.97628$. 
(4) The observation of electron microscopy shows that the surface of PLA sand barrier became messier as the number of revolutions increases. There's a positive linear.

\section{Acknowledgements}

This work was financially supported by the National Natural Science Foundation of China(3150030680), the Fundamental Research Funds for the Centrual Non-profit Research Institution of CAF (CAFYBB2016QB015) and the National Forestry Non-profit Industry Research Projects of China(201304305).

\section{References}

[1] Baoping Sun: Desertification Control Engineering (China Forestry Press, Beijing 2000) ( In Chinese)

[2] Yong Gao, Guoyu Qiu, Guodong Ding, Yingxing Qingshui, Yi Yu, Chunyuan Hu, Yanping Liu, Hefu Hubu, Yi Wang, Ji Wang: Joural of desert research Vol. 24 (2004), p. 365-370 ( In Chinese)

[3] Jianjun Qu, Yuquan Ling, Ruiping Zu, Kecun Zhang: Joural of desert research Vol. 25 (2005), p. 329-335( In Chinese)

[4] Zhenting Wang, Xiaojing Zheng: Joural of desert research Vol. 22 (2002), p. 229-232 ( In Chinese)

[5] Zhaofeng Chang, Shengnian Zhong, Fugui Han, Junhu Liu: Joural of desert research Vol. 20 (2000), p. 455-457 ( In Chinese)

[6] Xunming Wang, Guangting Chen: Joural of desert research Vol. 16 (1996), p. 180-184 ( In Chinese)

[7] Zhuchun Chen, Dingshu Li: Joural of desert research Vol. 7 (1987), p. 42-45( In Chinese)

[8] Zhi Dong, Hongli Li, Ji Wang, Guodong Ding, Baoping Sun: Science of Soil and Water Conservation Vol. 5 (2007), p. 35-39 ( In Chinese)

[9] Zhiwen Han, Xianwan Liu, Zhengyi Yao, Guosheng Shao: Joural of desert research Vol. 20 (2000), p. 40-44( In Chinese)

[10] Jianjun Qu, Xianwan Liu, Jiaqiang Lei, Fang Li, Zhiyong Yu: Joural of desert research Vol. 21 (2001), P. 276-280 ( In Chinese)

[11] Limin Yuan, Yong Gao: Inner Mongolia Forestry Science and Technology Vol. 36 (2010), p. 14-18, 39 ( In Chinese)

[12] Xiaohong Dang, Yong Gao, Yi Yu, Zhongju Meng, Jinrong Li, Limin Yuan, Minghui He, Hao Wu: Bulletin of Science and Technology Vol. 31 (2015), p. 41-46, 56 ( In Chinese)

[13] Limin Yuan, Yong Gao, Yi Yu, Qiuye Gong, Jingyu Jiang, Tiepeng Xing: Science of Soil and Water Conservation Vol. 8 (2010), P. 90-94 ( In Chinese)

[14] Qian Li, Yong Gao, Ji Wang, Dandan Zhou, Ruichun Ci: Science of Soil and Water Conservation Vol. 10 (2012), P. 69-74 ( In Chinese)

[15] Weijie Yuan, Yi Yu, Yongde Yue, Yong Gao, Yun Li, Xiaohong Dang, Huailiang Wang: Journal of Arid Land Resources and Environment Vol. 29 (2015), p. 166-171( In Chinese)

[16] Weijie Yuan, Yi Yu, Yong Gao, Luzhen Wang, Ge Wang: Journal of Inner Mongolia Agricultural University (NATURAL SCIENCE EDITION) Vol. 33 (2012), p. 108-102 ( In Chinese)

[17] Ling Chen, Shujuan Wang, Xiaolin Ma: Shanghai Textile Science and Technology Vol. 35 (2007), p. 46-47 (In Chinese) 
[18] Yong Qu, Jiaxian Bu: Journal of Textile Research Vol. 29 (2008), p. 48-51 ( In Chinese)

[19] Yuan Yang, Jianping Zhou, Yonggui Li: Shanghai Textile Science and Technology Vol. 36 (2008), p. 54-56 ( In Chinese)

[20]Mu Yao: Textile Materials Science (China Textile Press, Beijing 2015) (In Chinese)

[21] Aifen Feng, Yongjiu Zhang: Hebei Journal of Industrial Science \& Technology Vol. 29 (2012), p. 275-279 ( In Chinese) 